\title{
Multiscale environmental determinants of Leishmania vectors in the urban-rural context
}

\author{
María Gabriela Quintana 1,2,3,4* $\mathbb{0}$, María Soledad Santini ${ }^{3,4,5}$, Regino Cavia ${ }^{3,4,6}$, Mariela Florencia Martínez ${ }^{1}$, \\ Domingo Javier Liotta 1,7 , María Soledad Fernández ${ }^{3,4,8}$, Adriana Alicia Pérez ${ }^{8}$, José Manuel Direni Mancini ${ }^{2,3,4}$, \\ Sofía Lorian Moya ${ }^{1,3,4}$, Magalí Gabriela Giuliani ${ }^{1,4}$ and Oscar Daniel Salomón 1,3,4
}

\begin{abstract}
Background: In South America, cutaneous leishmaniasis (CL) and visceral leishmaniasis (VL) are emerging diseases, expanding in the border area of Argentina, Brazil and Paraguay. Outbreaks of CL were reported since the 1990s, with Nyssomyia whitmani as the main vector in this region. Regarding VL, urban reports started in 2010 with Lutzomyia longipalpis as the main vector. The aim of this study was to evaluate environmental determinants related to the main vectors of leishmaniasis, to contribute to the prevention and control response to the emergence of $V L$ and $C L$ in the Argentina-Brazil-Paraguay border region.

Methods: The cross-sectional survey includes two cities and two close rural areas in the Argentinean Northeast Region, between November 2014 and January 2015, with a total of 95 sampling sites. REDILA-BL traps were set for three consecutive nights, and a total of 68 meso- and microscale environmental and landscape characteristics were surveyed. The association between vector abundance with different variables was evaluated using a generalized linear model with zero-inflated negative binomial distribution. We analyzed females for detection of Leishmania DNA.

Results: The analysis for $L$. longipalpis indicates an excess of absences when the mean NDWI around the sites were higher. The abundance of Lu. longipalpis at mesoscale level was higher when more urban services were present, and when blood sources such as chickens or dogs at the microscale level were present. For Ny. whitmani, no variable was found to be associated with the absences, while its abundance increased in association with the following variables: percentage of tree cover, presence of garbage collection service, hosted people and, at microscale, the presence of poultry. Leshmania infantum DNA was detected in 2/49 (4\%) Lu. longipalpis.

Conclusions: The abundance of both species is influenced by variables at different scales, their influence probably has a hierarchy and they are acting on different aspects of the biology of these vectors. The urban spatial segregation of Lu. longipalpis and the peri-urban and rural segregation of $\mathrm{N}$. whitmani increase the risk of $\mathrm{VL}$ and $\mathrm{CL}$. The selection of the better variables for each scale will allow the design of appropriate control strategies depending on species.
\end{abstract}

Keywords: Lutzomyia longipalpis, Nyssomyia whitmani, Border area, Argentina

\section{Background}

In the last few decades in the New World leishmaniasis are re-emerging in some countries and emerging

\footnotetext{
*Correspondence: gabrieladelaquintana@gmail.com

${ }^{1}$ Instituto Nacional de Medicina Tropical, Administración Nacional de

Laboratorios e Institutos de Salud (ANLIS), Ministerio de Salud de la

Nación, Puerto Iguazú, Misiones, Argentina

Full list of author information is available at the end of the article
}

in others. Visceral leishmaniasis (VL) and cutaneous leishmaniasis $(\mathrm{CL})$ are neglected vector-borne diseases associated with environmental factors and their anthropogenic modifications [1]. Innovative and intensified surveillance practices were identified as priorities in the Pan American Health Organization (PAHO) "2016-2022 Action Plan" [2]. 
In Argentina, CL is mainly rural and endemic at least since the beginning of the 20th century, while VL is urban with recent epidemic events reported since 2006 [3]. Reporting of both leishmaniases in Argentina is mandatory. Autochthonous CL cases (with c.200 cases reported per year) are recorded from nine provinces, with scattered outbreaks, and the transmission currently occurs in rural domestic environments. Leishmania braziliensis is the main parasite species isolated from cases related to outbreaks, domestic mammals and vectors [4]. The abundance distribution of the vector and risk of transmission was associated with forest-rural/forest-culture ecotones, peri-urban deforestation, and climatic factors [4-7].

Phlebotomine surveillance was intensified in border areas since 2000 (due to southern reports of VL in Brazil and Paraguay) and Lu. longipalpis was found in Argentina at Clorinda (Formosa Province) in 2004 [8]. The first autochthonous human VL case with a concurrent case of canine VL and its vectors was recorded during 2006 in an urban area of Posadas (Misiones Province) [3, 9]. Since then, human cases have been reported in several urban scenarios of six provinces of Argentina, one of them with Migonemyia migonei as a vector [9-11]. There are now up to 158 cases reported with a fatality rate of $7.7 \%$ related mainly with co-morbidity in adults, while the proportion in the young is increasing. Social and commercial pet-related networks allowed the dispersion of canine VL thorough the country [9].

The Iguazú waterfall area, located in Iguazú Department where the city of Puerto Iguazú is the most important urban area, reported CL outbreaks in 1998 (Puerto Esperanza), 2004 (Urugua-í), and 2005 (Puerto Iguazú) $[12,13]$ and since then, regular cases are recorded every year. These cases are mainly related to deforestation, work forest-related risks, and peridomestic habitat close to the forest edge via the border effect $[7,14,15]$. Lutzomyia longipalpis was not found in the city of Puerto Iguazú before 2010 when was first found together with VL canine cases $[12,16]$. The studies already conducted in the city of Puerto Iguazú showed that the vector distribution was not uniform; phlebotomines were located in patches of higher abundance surrounded by more extensive areas where the vector was not found [17]. The aim of this study was to evaluate environmental determinants that influence in the occurrence and abundance of the main vectors of leishmaniasis, so to contribute to the prevention and control response to the emergence and dispersion of $\mathrm{VL}$ and $\mathrm{CL}$ in the Argentina-Brazil-Paraguay border region.

\section{Methods}

\section{Study area}

The study area belongs to the department of Iguazú $\left(25^{\circ} 35^{\prime} \mathrm{S}, 54^{\circ} 35^{\prime} \mathrm{W}\right)$ in the province of Misiones, northeast
Argentina, on the three-country border with Brazil and Paraguay, with an altitude between 140-240 m above sea level (Fig. 1a, b). The studied area includes the city of Puerto Iguazú $\left(25^{\circ} 35^{\prime} \mathrm{S}, 54^{\circ} 35^{\prime} \mathrm{W}\right)$, the village of Puerto Libertad $\left(25^{\circ} 39^{\prime} \mathrm{S}, 54^{\circ} 26^{\prime} \mathrm{W}\right)$ and the surrounding rural and natural areas (Fig. 1c-f). The phytogeographical region is classified as Paranaense Forest, a subtropical humid forest from the Amazonian domain [18]. The weather is subtropical without a dry season and hot summers [19]. The mean minimum temperature and maximum temperatures are $11{ }^{\circ} \mathrm{C}$ and $32{ }^{\circ} \mathrm{C}$, respectively. Rainfall is abundant throughout the year with average annual values of $2000 \mathrm{~mm}$ (Data from the National Meteorological Service, https://www.smn.gob.ar/estadisticas).

The city of Puerto Iguazú is limited by the Paraná and Iguazú rivers, that are also the international border with Paraguay and Brazil, and by the Iguazú National Park and the Peninsula Provincial Park. The village of Puerto Libertad is located along the Paraná river, $35 \mathrm{~km}$ to the south of the city of Puerto Iguazú (Fig. 1b). The selected area allowed us to study a broad range of environments from natural reserves to urban courtyards (urban, periurban, rural and forest), with different social groups in risk. All the sampled sites were geolocated by GPS and mapped (Fig. 1c-f).

\section{Sampling design}

Regarding the urban and periurban environments, we divided Puerto Iguazú and Puerto Libertad into a grid of $400 \mathrm{~m}^{2}$ squares based on Fernández et al. [20] $(n=55$ in Puerto Iguazú and $n=15$ in Puerto Libertad) (Fig. 1c, d). In the urban and periurban environments, within each square of the grid one household was selected using the 'critical site' criterion, empirical criterion that involves the most favorable peridomestic environment for the vector in a given area (previously denominated 'worst scenario' [21]), and sampled from 26th November to 2nd December 2014.

Rural and forest environments were sampled according to the patch size along transects: "Cooperativa" $\left(25^{\circ} 56^{\prime} \mathrm{S}\right.$, $54^{\circ} 32^{\prime} \mathrm{W}$ ) with 13 sites (9 rural and 4 forest sites, Fig. 1e) and "San Cayetano" $\left(25^{\circ} 50^{\prime} \mathrm{S}, 54^{\circ} 31^{\prime} \mathrm{W}\right)$ with 12 sites $(10$ rural and 2 forest sites, Fig. 1f). Each trap REDILA-BL [22] was placed at least $100 \mathrm{~m}$ apart from each other. In rural areas, we selected houses with the critical site criterion mentioned above, while in forest areas the sampled sites were placed below the dense canopy. Sites were sampled during 13-22 January 2015.

\section{Phlebotominae sampling}

The phlebotomines were captured with a light trap REDILA-BL (INMeT IT, Iguazú, Argentina) set for three 
consecutive nights without rain or wind [22], with a total sampling effort of 274 trap-nights. In houses (urban, periurban and rural sites) 95 traps per night were located in the peridomestic courtyards in an animal shelter (if it was available) or in a shadowy area. In forest sites traps were located hanging from a tree branch. In all the sites the traps were located approximately at $1.5 \mathrm{~m}$ above the ground, and they were active from 16:00 $\mathrm{h}$ to $8: 00 \mathrm{~h}$.

All specimens were kept in a freezer, then separated into fed females, unfed females and males, and counted under a microscope $40 \times$ (Zeiss $\odot$, Jena, Germany). The identification was performed according to Galati [23]; abbreviations by Marcondes are followed [24]. As Evandromyia cortelezzii and E. sallesi females cannot be discriminated at the species level by morphology, individuals are reported as Cortelezzii complex [25].

\section{Leishmania infantum DNA detection}

Up to 30 females of each trap/night were separated for molecular analyses, identified by abdominal segment dissection and observation of the spermathecae, while keeping the remnant parts of each specimen individually in $1.5 \mathrm{ml}$ microtubes and kept it at $-20^{\circ} \mathrm{C}$ until DNA extraction followed by polymerase chain reaction (PCR). Total DNA was extracted using a commercial kit (DNA Puriprep-S, Cat\# K1205-250, INBIO HIGHWAY ${ }^{\circledR}$ Tandil, Argentina) according to the manufacturer's instruction. DNA quality was evaluated by a PCR assay targeting the constitutive gen IVS6 (cacophony) of Phlebotominae, giving an expected 220-bp product with the primers 5Llcac (5'-GGC CCA CTA TTA CAC CAA CCC C-3') and 3Llcac (5'-GGG GTA GGG GCG TTC TGC GAA-3') [26]. Detection of Le. infantum was conducted following the RV1-RV2 PCR protocol as described by Lachaud et al. [27], which targets the highly repetitive kinetoplast (mitochondrial) DNA generating an amplicon of 145 bp using the primers RV1 (5'-CTT TTC TGG TCC CGC GGG TAG G-3') and RV2( $5^{\prime}$-CCA CCT GGC CTA TTT TAC ACC A-3'). A confirmed isolated strain of Le. infantum was employed as a positive control; negative controls consisted of water; the reference strain used was WHO Le. braziliensis HOM/BR75M2903. All PCR products were separated by electrophoresis on a $2 \%$ agarose gel and visualized with SyberGreen ${ }^{\circledR}$ (Invitrogen ${ }^{\mathrm{TM}}$, Carlsbad, USA). For sequencing purposes, PCR products were purified by a commercial kit (DNA Puriprep-S, Cat\# K1205-250, INBIO HIGHWAY ${ }^{\circledR}$ ) from the agarose gel. Sequence qualities were evaluated with Codon Code Aligner $^{\text {TM }}$ software (V 2.0.6-LaBiMAp-FCEQyN-UNaM license), and Le. infantum identity was confirmed by BLASTn (blast.ncbi.nlm.nih.gov/Blast).

\section{Variable selection by scale and study sites}

At each site, we performed an epidemiological-environmental characterization. Characteristics surveyed followed a hierarchical ecological scale previously defined for the local phlebotomine species by a workshop in the frame of the IDRC Project\# 107577 and already applied by Santini et al. [28] and Tomhaz-Soccol et al. [29]. We include in the analyses micro- and mesoscale factors that affect the presence and abundance of Phlebotominae species, in order to evaluate the environmental variables in each scenario.

Different surface buffer areas were considered at a radius of $c .25,50,100$ and $250 \mathrm{~m}$. At the spatial mesoscale (buffer at a radius of $>25 \mathrm{~m}$ from the trap location site), environmental characteristics were evaluated using the percentages of different land cover classes and vegetation indices. Land cover classes were defined ad-hoc based on previous phlebotomine studies [28, 29] and included: (i) trees or shrubs; (ii) herbaceous vegetation; (iii) crops; (iv) bare soil; (v) impervious or constructed surfaces; and (vi) water bodies. The percentages of each of the six land cover classes were estimated within circular areas centered at each sampled site. Likewise, the average value of the normalized difference vegetation index (NDVI) and normalized difference water index (NDWI) for each pixel of the image was calculated using the four buffer sizes mentioned above [30,31].

We used a Spot5-HRG2 multispectral image of the study area on 20 December 2014 (grids) and 24 December 2014 (transects) with a spatial resolution of $2.5 \mathrm{~m}$. Vector Support Machine (SVM) classifier was used to generate coverage maps. The configuration used for the SVM classifier was: (i) Kernel function $=\mathrm{RBF}$; (ii) Constant $C=1000$; (iii) Gamma parameter $=1$; and (iv) Probability threshold $=0$. To increase the precision of the classification of the maps, the homogeneity variable was used [32]. Accuracy of the classification was evaluated with the kappa and precision indices [33].

Satellites and spatial data were analyzed using ENVI+IDL v.4.8 (ITT Visual Information Solutions, https:/envi.software.informer.com/4.8/) and Quantum Gis 2.14.15-Essen [34], respectively. Also, at the mesoscale, 7 street characteristics and urban service availability were recorded (Table 2).

At the microscale, defined as the environment around the trap location site equal or up to $25 \mathrm{~m}$ (peridomestic or forest), we recorded 21 environmental characteristics (Table 2). Mesoscale and microscale environmental characteristics were recorded in the field simultaneously with the entomological surveys. 


\section{Data analysis}

In each of the 95 sampled sites, the abundance of each phlebotomine species was estimated using the trap success [35], i.e. the number of individuals captured per trapping effort (number of nights the trap actually worked). To evaluate if the Phlebotominae assemblage structure was adequately described by the sampling effort in the urban/periurban area of the city of Puerto Iguazú, the urban/periurban area of Puerto Libertad, and the rural and the forest transects, we computed the rarefaction curves based on the results [36]. Since urban/periurban is actually an environmental gradient, we did not consider these as different categories. For these analyses, all individuals captured in the three nights at each site were considered a sampling unit.

Phlebotominae assemblages were analyzed in relation to land cover class using a canonical correspondence analysis (CCA) [37]. Rare species (occurring only at one site) were removed from this analysis. This analysis was performed using species abundance at each site as a response variable and the different land cover classes and indices described in the variable selection section as explanatory variables. A backward selection procedure was carried out to exclude the variables that did not explain phlebotomine assemblage structure. The area (equivalent to buffers of 25 , 50,100 and $250 \mathrm{~m}$ ) that best explained the abundance of phlebotomine was evaluated for each class. For this purpose, the results by area were compared using pseudo- $R^{2}$ through multiple regression models including all the measured variables. For this explanatory analysis, generalized linear models with Poisson distribution and log-link were used [38]. These analyses were performed using vegan [39] and base packages in R software [40].

\section{Association between Ny. whitmani and Lu. longipalpis abundance and environmental variables}

As our samples contained large numbers of zeros (Table 1), we used zero-inflated (ZI) count models to analyze the association between the abundance of the two most important species from a public health perspective, $N y$. whitmani and Lu. longipalpis, and the environmental variables.

ZI models are mixture models with two independent components: the 'zero-inflated' component, which represents the excess of absences (the absences not predicted by the count component of the model, that can be both true and false absences); and the component that represents the counts, including the absences expected in the count process [38]. For this component, we used negative binomial distribution to take into account the overdispersion found in the count process $[38,41]$.

Two sets of explanatory variables were evaluated, according to the spatial scales previously defined: mesoscale (buffer $>25 \mathrm{~m}$ ) and microscale (buffer $<25 \mathrm{~m}$ ). The number of hosted people was $\log (\mathrm{x}+1)$-transformed when used as a predictor to decrease the leverage of extreme values.

We fitted univariate regression models for each explanatory variable, and those significant at $P<0.1$ were retained. Based on the results of the univariate analysis, and those that were found significant, our strategy was to formulate multiple models containing explanatory variables from each of the two sets. To avoid overfitting and multicollinearity issues, the explanatory variables with strong correlation were evaluated in separate models. We examined several possible additive combinations of variables to determine the final model. The most parsimonious model was chosen based on Akaike's information criterion (AIC). The analyses were conducted using pscl and lmtest packages in R version 3.4.3 [40].

After the model selection procedure, spatial predictions of the abundance of both species in the city of Puerto Iguazú with a resolution of $30 \times 30 \mathrm{~m}$ were built using maps of the predictive variables when they were available or assuming constant values for the whole area for different levels of those variables (see Results).

\section{Results}

A total of 594 phlebotomines were captured in 274 trap/nights at 95 sites (Table 1). The number of species obtained with the overall captures was 10, but just 3 in forest sites, 3 in rural sites, 8 in periurban and 7 in urban sites (Fig. 2). The prevalent species were Lu. longipalpis (47\%) and Ny. whitmani (45\%), while the remaining 8 species of the Phlebotominae represented each one less than $2.5 \%$ of the overall capture. Rarefaction curves suggest that rural phlebotomine assemblages were adequately sampled with the effort used, while in urban and periurban areas some species could be still missed, and in the forest, more sites are required to be sampled (Fig. 2).

A very good environmental classification was observed for the study area using the SVM classifier (image from 20/12/2014: kappa $=0.9873$, precision $=98.9520 \%$; image from 24 December 2014: kappa $=0.9699$, precision $=97.5235 \%$ ). The exploratory analysis indicated that most of the variance of $L u$. longipalpis abundance was explained using land cover class percentages registered at a $250-\mathrm{m}$ radius area, while for $N y$. whitmani it was at 50-m radius area.

For both species, the characteristics recorded at a $100-\mathrm{m}$ radius area explained the second highest amount 

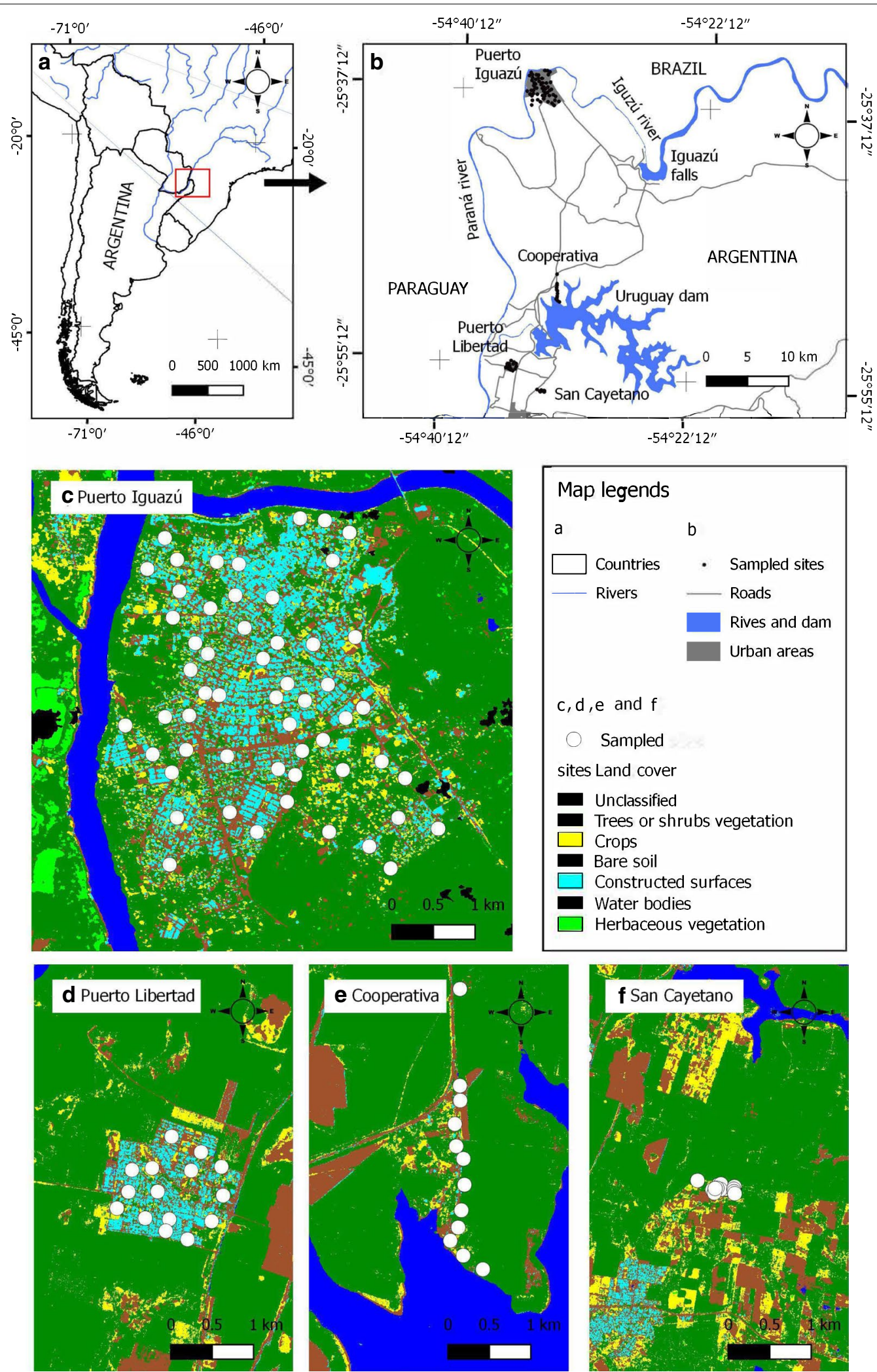

Fig. 1 Study area (a, b) and distribution of the sampling sites ( $\mathbf{c}-\mathbf{f})$ of phlebotomines in Puerto Iguazú Department, Misiones, Argentina 
of variance. Therefore, we decided to conduct assemblage analysis using variables at the $250-\mathrm{m}$ radius area for Lu. longipalpis, and variables at the $50-\mathrm{m}$ radius area for $N y$. whitmani.

After removing the sites without captures or only with captures or rare species. The first two axes of the CCA were significant $(P<0.05)$ representing $32.6 \%$ of the total variability in the phlebotomine abundance in the sites (CCA1: 20.5\%; CCA2: 12.1\%). The first axis discriminated urban sites with $\mathrm{Lu}$. longipalpis and Pintomyia monticola grouped in the most urbanized environments of the city of Puerto Iguazú, while $N y$. whitmani, Mg. migonei, Cortelezzii complex and Micropigomyia quinquefer were comparatively more abundant in sites with a mixed landscape. These differences were explained by the differences in the percentage of tree or shrub vegetation cover, mean NDWI values and the number of land cover classes which was comparatively higher in periurban sites (Fig. 3). The second axis discriminated forest and rural sites, where $N y$. neivai and Brumptomyia sp. were more abundant, from urban and periurban sites. These differences were explained by the variations in the number of land cover classes and in the mean NDWI that were comparatively higher in the forest and rural sites (Fig. 3).

\section{ZINB models}

The zero-inflated component of the analysis indicate an excess of absences of $L u$. longipalpis when the buffer of $250 \mathrm{~m}$ radius around the trapping site has high mean values of NDWI, regarding to this index values where $L u$. longipalpis is present (Table 3 ).

According to the count component results, the abundance of Lu. longipalpis was higher when more urban services were present (drinking water service, garbage collection service and public sewer connection), and when blood sources such as chickens or dogs were present at the microscale level (Table 3). According to these results, spatial predictions for Lu. longipalpis abundance (Fig. 4) were built with the map of the mean NDWI using moving windows of a $250-\mathrm{m}$ radius area. We assumed different constant values for drinking water service, garbage collection service, public sewer connection (dummy variables or up to three constant values within the known range in the field for quantitative ones); and chickens, dogs or both, since this information is not available on maps for the study area. So, in absence of urban services, with or without animals (chickens or dogs, Additional file 1: Figure S1), a very low abundance of $\mathrm{Lu}$. longipalpis (less than 1 individual in 3 trapping nights) in the whole area was predicted. While if urban services and animals would be present in the household, the higher abundances are predicted in the central area of the city where NDWI showed lower values, reflecting the lower vegetation cover conditions (Fig. 4a-c).

For Ny. whitmani, no variable was found associated with the excess of absences, while the count component showed that the highest abundance of this vector was observed in sites with a higher percentage of tree cover at a 50-m radius area, with garbage collection service at the mesoscale level, with a high number of hosted people in the house, and with the presence of poultry at the microscale level (Table 4).

Five sampling sites were removed from this analysis due to missing data for the variable number of hosted people. Spatial predictions for $N y$. whitmani abundance were built with the map of the percentage of tree cover of the study area using moving windows of a $50-\mathrm{m}$ radius area. We assumed different constant values for garbage collection service, number of hosted people and poultry presence, since this information is not available on maps for each house of the whole study area. In the absence of garbage collection service and poultry, abundance of less than $1 N y$. whitmani in 3 trapping nights (Additional file 1: Figure S1) was predicted. When garbage collection service and poultry were present in the houses, the higher abundances of $N y$. whitmani were predicted in the peripheral areas of the city as a result of the higher percentage of tree cover in those areas (Fig 4e, f).

\section{PCR results}

One hundred and seventy females (9 with blood content in the gut and the remaining with no blood detected by optical means) were screened for Le. infantum DNA detection resulting in $2 \mathrm{Lu}$. longipalpis (1 recently fed and 1 without observed blood) positive by PCR. This was confirmed by sequence analysis showing $99 \%$ identity with reference sequences deposited on GenBank. Considering the total abundance of $L u$. longipalpis analyzed, the infection rate was $4 \%$ (2/49), from both sites of Puerto Iguazú.

\section{Discussion}

The spatially segregated prevalence of urban Lu. longipalpis and periurban-rural $N y$. whitmani in the area of the Argentina-Brazil-Paraguay border has already been described [29, 42]. The rarefaction curves suggest that the peridomestic environment in rural landscapes seems stable and homogeneous enough to make the captures representative of their phlebotomine assemblages.

The rarefaction curve for urban-periurban captures indicates that the captures conducted may have missed some species. But unlike the rural area, at least in the southern latitude localities of South America, the urban-periurban peridomestic environments have 
Table 1 Description of the environmental variables evaluated at the micro- and mesoscale on the Argentine side of the border with Paraguay and Brazil

\begin{tabular}{|c|c|c|c|}
\hline Scale & Variable & Description & Value \\
\hline \multirow[t]{17}{*}{ Mesoscale } & Tree_25-50-100-250 & Percentage of tree cover at different buffers & 0 to 100 \\
\hline & Herbaceous_25-50-100-250 & Percentage of herbaceous cover at different buffers & 0 to 100 \\
\hline & Soil_25-50-100-250 & Percentage of soil cover at different buffers & 0 to 100 \\
\hline & Urban_25-50-100-250 & Percentage of impervious cover at different buffers & 0 to 100 \\
\hline & Water_25-50-100-250 & Percentage of water cover at different buffers & 0 to 100 \\
\hline & Crops_25-50-100-250 & Percentage of crops cover at different buffers & 0 to 100 \\
\hline & N_cob_25-50-100-250 & Cover number & 1 to 6 \\
\hline & Shannon_25-50-100-250 & Diversity index & 0 to 5 \\
\hline & Ndvi_25-50-100-250 & Average value of the NDVI index & 0 to 1 \\
\hline & Ndwi_25-50-100-250 & Average value of the NDWI index & 0 to 1 \\
\hline & Paved road & Presence/absence & Yes/No \\
\hline & Drinking water service & Presence/absence & Yes/No \\
\hline & Electrical energy & Presence/absence & Yes/No \\
\hline & Garbage collection service & Presence/absence & Yes/No \\
\hline & Public sewer connection & Presence/absence & Yes/No \\
\hline & Street lighting & Presence/absence & Yes/No \\
\hline & Servic_index & $\begin{array}{l}\text { An index of public services was constructed from the presence of } 6 \text { services from } 0 \text { (no service) to } \\
1 \text { (all services) }\end{array}$ & 0 to 1 \\
\hline \multirow[t]{21}{*}{ Microscale } & Houses garbage & Area covered with garbage from an area $>1 \mathrm{~m}^{2}$, to $<1 \mathrm{~m}^{2}$, to an area without garbage & $0,1,2$ \\
\hline & Fallen leaves and fruits & $\begin{array}{l}\text { Area covered with fallen leaves and fruits from an area }>1 \mathrm{~m}^{2} \text {, to }<1 \mathrm{~m}^{2} \text {, to an area without fallen } \\
\text { leaves and fruits }\end{array}$ & $0,1,2$ \\
\hline & Flooded land & Area flooded $>1 \mathrm{~m}^{2}$, or $<1 \mathrm{~m}^{2}$, or no flooded area & $0,1,2$ \\
\hline & Land & Presence in $10 \times 10 \mathrm{~m}$ around the trap & Yes/No \\
\hline & Lawn & Presence in $10 \times 10 \mathrm{~m}$ around the trap & Yes/No \\
\hline & Shrubs & Presence in $10 \times 10 \mathrm{~m}$ around the trap & Yes/No \\
\hline & Trees & Presence in $10 \times 10 \mathrm{~m}$ around the trap & Yes/No \\
\hline & Cement & Presence in $10 \times 10 \mathrm{~m}$ around the trap & Yes/No \\
\hline & Chicks & Presence/absence & Yes/No \\
\hline & Insecticide & Use of insecticides & Yes/No \\
\hline & Hosted people & No. of people sleeping the night before sampling & 0 to 15 \\
\hline & Rodents & Presence/absence (by recall of householders) & Yes/No \\
\hline & Weasels & Presence/absence (by recall of householders) & Yes/No \\
\hline & Small mammals & Presence/absence, mix rodents + weasels (by recall of householders) & Yes/No \\
\hline & Chickens & Presence/absence & Yes/No \\
\hline & Rchickens & The variable was recoded based on the no. of chickens $\left(n=0,1 \geq n \leq 10, n^{>} 10\right.$, respectively) & $0,1,2$ \\
\hline & Dogs & Presence/absence & Yes/No \\
\hline & Ndogs & No. of dogs & 0 to 8 \\
\hline & Rdogs & 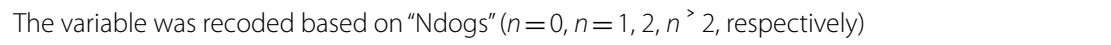 & $0,1,2$ \\
\hline & Positive baits & Proportion of positive baits & 0 to 1 \\
\hline & Baits & $\begin{array}{l}\text { Refers to which blood sources were present around the trap }(1 \times 1 \mathrm{~m}) \text { : } 0 \text { (none), } 1 \text { (dogs present), } 2 \\
\text { (chickens present) and } 3 \text { (dogs and chickens present) }\end{array}$ & \\
\hline
\end{tabular}

a micro-heterogeneous landscape with green patches intermingled with houses of different quality and paved streets, that could change with sudden trends of unplanned urbanization or land occupation. Furthermore, these green patches are contiguous with riparian forests or city belt secondary woods. In this sense, the presence of species of the genus Brumptomyia in these sites is an indicator of closeness to undisturbed environments $[43,44]$. Therefore, this heterogeneous, dynamic urban-periurban and forest-edged landscape allows to sporadically host a great diversity of species with different pressure to be adapted to the anthropized habitat, 
Table 2 Sites with the presence of phlebotomines (\%) and abundance total of individuals captured (\%) by species, urban-periurban locality (Puerto Iguazú, Puerto Libertad), rural, rural and forest environments (Cooperativa, San Cayetano), province of Misiones, 20142015, Argentina

\begin{tabular}{|c|c|c|c|c|c|c|c|c|}
\hline \multirow{2}{*}{$\begin{array}{l}\text { Site } \\
\text { Species }\end{array}$} & \multicolumn{2}{|c|}{ Puerto Iguazú $(n=55)$} & \multicolumn{2}{|c|}{ Puerto Libertad $(n=15)$} & \multicolumn{2}{|c|}{ Rural $(n=19)$} & \multicolumn{2}{|c|}{ Forest $(n=6)$} \\
\hline & $\begin{array}{l}\text { Presence } \\
n(\%)\end{array}$ & $\begin{array}{l}\text { Abundance } \\
n(\%)\end{array}$ & $\begin{array}{l}\text { Presence }^{\mathrm{a}} \\
n(\%)\end{array}$ & $\begin{array}{l}\text { Abundance } \\
n(\%)\end{array}$ & $\begin{array}{l}\text { Presence }^{a} \\
n(\%)\end{array}$ & $\begin{array}{l}\text { Abundance } \\
n(\%)\end{array}$ & $\begin{array}{l}\text { Pressence }^{a} \\
n(\%)\end{array}$ & $\begin{array}{l}\text { Abundance } \\
n(\%)\end{array}$ \\
\hline Lu. longipalpis & $16(29.09)$ & $277(49.03)$ & $0(0)$ & $0(0)$ & $0(0)$ & $0(0)$ & $0(0)$ & $0(0)$ \\
\hline Mg. migonei & $2(3.64)$ & $6(1.06)$ & $0(0)$ & $0(0)$ & $0(0)$ & $0(0)$ & $0(0)$ & $0(0)$ \\
\hline Ny. neivai & $2(3.64)$ & $2(0.35)$ & $0(0)$ & $0(0)$ & $3(15.79)$ & $4(17.39)$ & $2(33.33)$ & $2(35.71)$ \\
\hline Ny. whitmani & $16(29.09)$ & $254(44.96)$ & $0(0)$ & $0(0)$ & $5(26.32)$ & $15(65.22)$ & $0(0)$ & $0(0)$ \\
\hline Brumptomyia sp. & $5(9.09)$ & $7(1.24)$ & $0(0)$ & $0(0)$ & $2(10.53)$ & $4(17.39)$ & $2(33.33)$ & $3(50)$ \\
\hline Pa. bigeniculata & $0(0)$ & $0(0)$ & $0(0)$ & $0(0)$ & $0(0)$ & $0(0)$ & $1(16.67)$ & $1(14.29)$ \\
\hline Pi.monticola & $3(5.45)$ & $4(0.71)$ & $0(0)$ & $0(0)$ & $0(0)$ & $0(0)$ & $0(0)$ & $0(0)$ \\
\hline Pi.pessoai & $1(1.82)$ & $1(0.18)$ & $0(0)$ & $0(0)$ & $0(0)$ & $0(0)$ & $0(0)$ & $0(0)$ \\
\hline Mi. quinquefer & $2(3.64)$ & $8(1.42)$ & $0(0)$ & $0(0)$ & $0(0)$ & $0(0)$ & $0(0)$ & $0(0)$ \\
\hline Cortelezzii complex & $2(3.64)$ & $2(0.35)$ & $0(0)$ & $0(0)$ & $0(0)$ & $0(0)$ & $0(0)$ & $0(0)$ \\
\hline$X X^{b}$ & $2(3.64)$ & $4(0.71)$ & $0(0)$ & $0(0)$ & $0(0)$ & $0(0)$ & $0(0)$ & $0(0)$ \\
\hline Total & $25(45.45)$ & $565(100)$ & $0(0)$ & $0(0)$ & $7(36.84)$ & $23(100)$ & $2(33.33)$ & $6(100)$ \\
\hline
\end{tabular}

a The presence by species was determined such as the appearance of at least one specimen on any of the sampling nights

b Not identified to the species level due to deterioration of the specimens

but few prevalent species actually adapted to it. The phlebotomine populations from the forest environment were sampled in this study just for comparative purposes, and so they were underrepresented as shown in the rarefaction curve. The forest is usually an environment more stable than the urban or rural one, with lower captures and the highest richness $[7,45]$. To describe the forestrelated populations properly a greater capture effort is required, but also a differentiated strategy of trapping due to the different strata in altitude related to the canopy, the lack of blood sources nearby the placement of traps that could affect the captures. Therefore, to avoid sporadic or unrepresented species in the modeling, only the well-represented species were analysed $[15,17,46]$.

Thus, phlebotomine diversity both in rural and urban environments is related to the heterogeneity of the landscape. In urban environments, the presence of vegetation offers multiple microhabitats as resting-breeding sites. The CCA analysis showed that the species assemblage structure is associated with the amount of land cover classes, the percentage of woody plants and NDWI. It is important to note that greater diversity was expected in forest and periurban environments as presented in a previous study in the Argentinean area [45], which was probably not achieved as the sampling effort did not reach the optimal threshold of the curve. In catches from the Brazilian side in equivalent environments, the same trend was observed except in the rural environment where the authors detected higher species richness with greater sampling effort [29]. The CCA analysis allows the discrimination between species well adapted to urban environments such as Lu. longipalpis-Pi. monticola from periurban environments that are less adapted or species that are in the state of an ongoing adaptation to the more heterogenous anthropized environments such as $N y$. whitmani-Mg. migonei, and species from the rural-forest environments such as Ny. neivai-Brumptomyia sp.

This result reasserts the spatial segregation of the species, and the role of the genus Brumptomyia as an indicator of environmental health. The sites or season with higher abundance in urban settings are usually not coincidental with $\mathrm{Lu}$. longipalpis [47-50].

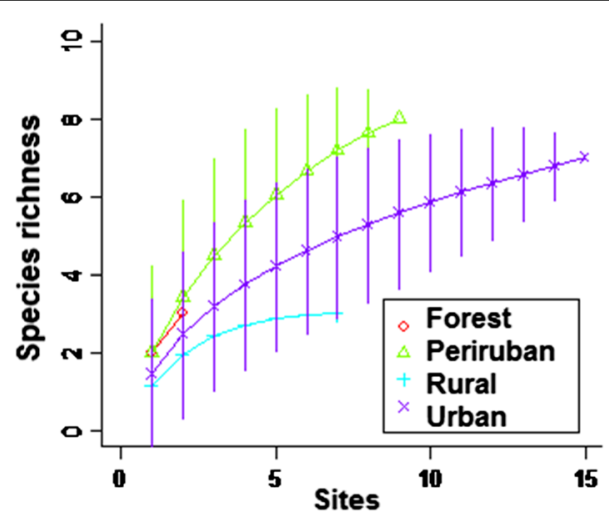

Fig. 2 Rarefaction curves based on sampling effort by site for four different environments comparing species richness 
In other ecoregions of Argentina, $N y$. neivai is the main vector of Le. braziliensis and also of peridomestic CL, but in the province of Misiones it is related to outbreaks of CL associated with deforestation fronts, while $N y$. whitmani is the incriminated vector in the studied area $[4,9]$. The association of Pi. monticola with the urban gradient together with $\mathrm{Lu}$. longipalpis, in three different trappings sites separated from each other by up to $1000 \mathrm{~m}$, requires further sampling.

Consistently with the urban distribution and microhabitat suitability for $\mathrm{Lu}$. longipalpis, we found a lower probability of finding this vector where higher values of NDWI are present in a 250-m radius area, conditions presented mainly in forest and rural landscapes. We assumed that the absence of Lu. longipalpis in these areas with high values of NDWI are true absences rather than sampling bias, as could respond to environmental suitability requirements of this species. Abundance of $\mathrm{Lu}$. longipalpis is greatest when more public services are present in the dwelling, associated also with the presence of a food source at the microscale level, reflecting an urban environment but with food availability. An interesting result of the present models is that each species is associated to different variables at different scales; for example Lu. longipalpis at the mesoscale level does not need trees but at the microscale level is associated with trees if a source of food is within reach. Models combining variables at different scales represent different risk scenarios, which allow the identification of the type of environment at the time of implementing effective control and/or surveillance strategies.

When the spatial distribution of Lu. longipalpis through Puerto Iguazu was predicted in $250 \mathrm{~m}$ mesoscale windows (the scale that better explains the variance of abundance of this species), with actual NDWI values, most of the urbanized area was suitable for $L u$. longipalpis. The forecasted distribution of this species is concentrated along the main avenue on the vertical axis, more than in the peripheral more homogeneous and forested areas. This broad distribution was associated also with dogs as a source of blood and urban services as a proxy of landscape microheterogeneity. However, when chickens were included in the predictive maps with or without dogs, a few "hot spots" of vectors were spatially segregated.

The association between Lu. longipalpis "hot spots" and chickens, blood-meal availability, and tree coveragelandscape heterogeneity in urban settings were already described in the same ecoregion [21, 29, 45, 46] and the role of chickens also in other regions [51]. Breeding chickens for subsistence in the relatively small backyards within the city allows a steady blood source for the vectors, and so highlight the inconvenience to think about poultry-based zooprophylaxis. Contrarily, the dogs may be a driver for vectors dispersion within the city, besides parasites. Regarding the NDWI, the tolerance of $\mathrm{Lu}$. longipalpis of low levels of humidity could help to the urbanization and adaptation of this species to anthropized
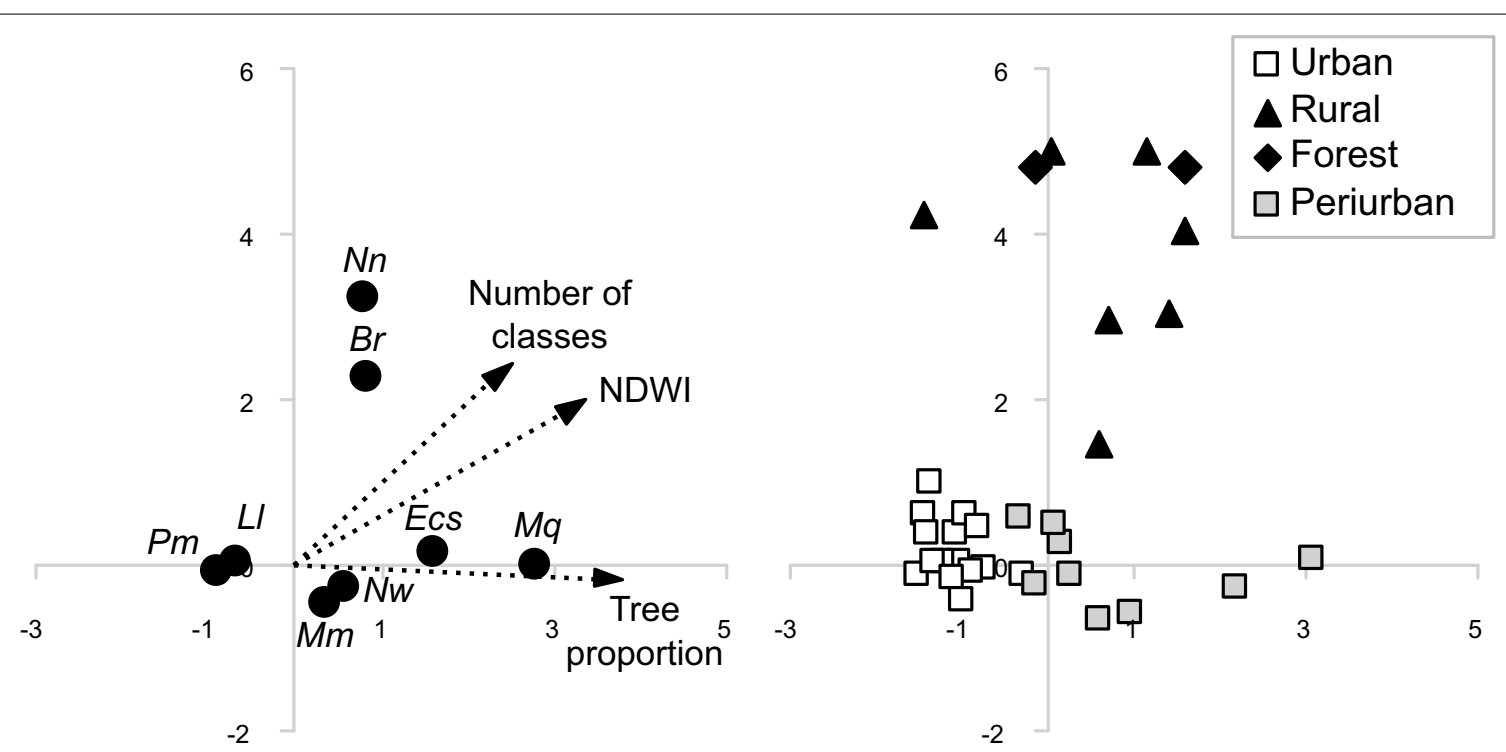

Fig. 3 Canonical correspondence analysis (CCA) for species of the Phlebotominae and environmental variables (100-m radius area). In the figure on the right, the distribution of the different environments is represented. Abbreviations: Br, Brumptomyia sp.; Nn, Ny. neivai; Lu, Lu. longipalpis; Pm, Pi. monticola; Ec, Ev. cortellessii-sallesi; Nw, Ny. whitmani 
Table 3 Parameter estimates of the zero-inflated negative binomial models for Lutzomyia longipalpis abundance

\begin{tabular}{|c|c|c|c|c|c|c|}
\hline \multirow[t]{2}{*}{ Variable } & \multicolumn{3}{|c|}{ Negative binomial } & \multicolumn{3}{|c|}{ Zero-inflated } \\
\hline & Coefficient & SE & $P$-value & Coefficient & SE & $P$-value \\
\hline Intercept & -4.44 & 1.55 & 0.004 & -1.95 & 1.32 & 0.14 \\
\hline \multicolumn{7}{|l|}{ Mesoscale } \\
\hline Mean NDWI in 250-m radius area & & & & 17.84 & 7.51 & 0.018 \\
\hline Drinking water service & 1.01 & 0.36 & 0.005 & & & \\
\hline Garbage collection service & 3.21 & 1.19 & 0.007 & & & \\
\hline Public sewer connection & 0.74 & 0.34 & 0.032 & & & \\
\hline \multicolumn{7}{|l|}{ Microscale } \\
\hline \multicolumn{7}{|l|}{ No dogs or chickens } \\
\hline Dogs & 2.98 & 0.95 & 0.002 & & & \\
\hline Chickens & 3.45 & 0.95 & $<0.001$ & & & \\
\hline Both & 2.68 & 1.00 & 0.007 & & & \\
\hline
\end{tabular}

Notes: Parameters estimated are shown in the linear predictor scale. AIC: 191.44 (null model: 214.44); 85 residuals degrees of freedom

(See figure on next page.)

Fig. 4 Spatial predictions for the abundance (number of individuals collected during three nights) of Lu. longipalpis (a-c) and Ny. whitmani (d-f). a With all urban services and with dogs and chickens present. $\mathbf{b}$ With all urban services and only dogs present. $\mathbf{c}$ Wit all urban services and only chickens present. $\mathbf{d}$ Without garbage collection, 5 hosted people and with chickens. e With collection of waste, 5 hosted people and chickens. $\mathbf{f}$ With collection of waste, 10 hosted people and chickens

environments [52], while at the mesoscale, the environmental variables associated with $L u$. longipalpis suggest a broad plasticity that facilitates a step by step spread within the city $[20,21]$.

Discrimination of variables associated with the distribution of $\mathrm{Lu}$. longipalpis at two spatial scales rise the possibility to design two different sets of interventions of integrated vector management at the urban operational level, but always acting on both scales simultaneously with proper indicators of impact. In Santo Tomé, a city in the same ecoregion of this study, the microscale variables were found to be associated with the abundance of Lu. longipalpis, while the mesoscale the variables were associated both with the presence/absence and abundance of this species [17]. Of course, urban services, paved streets or distance to the river are not modifiable variables but other variables were associated with "hot spots" at different scales including the microscale site of collection. For instance, the recommendations could include planned vegetation coverage with selected tree species, few plant-pots and deforested belts to increase the distance from forest edge, improved quality of houses (openness), garbage management and water drainage, reduced accessibility to chickens or other bloodmeal sources (by increasing the distance from pens to house) $[5,7,20,21,53-56]$.
Another issue to support the idea of focused control on the "hot spots" is the possibility that these sites act as source populations for the remaining low-abundance sites. The longitudinal studies suggest that the clustering of urban $\mathrm{Lu}$. longipalpis is persistent in time with most "hot spots" of steady abundance, while other sites with occurrence of $\mathrm{Lu}$. longiplapis could appear-disappear due to microenvironment changes [42, 57-60]. Therefore, for modeling the vector "hot spot" abundance along time based on climatic variables (temperature, land surface temperature, and indirect related variables NDVI and NDWI) lag-times and seasonal associations should be considered [47, 61-63] instead of same day of capture data. This lag approach could provide a forecasting tool that reflects actual changes in cohorts of vector populations instead of the daily activity. The studies that include temporality, should also need to characterize the stage of colonization of the urban area by $L u$. longipalpis as the species abundance could increase up to 60 times from the first reports to an established population [20,63].

The distribution of $N y$. whitmani related to the periurban, more relatively homogeneous landscape, by ZINB modeling only show association in the count component at the mesoscale with vegetation coverage and garbage collection and at the microscale with two sources of blood, poultry and humans. Therefore, 


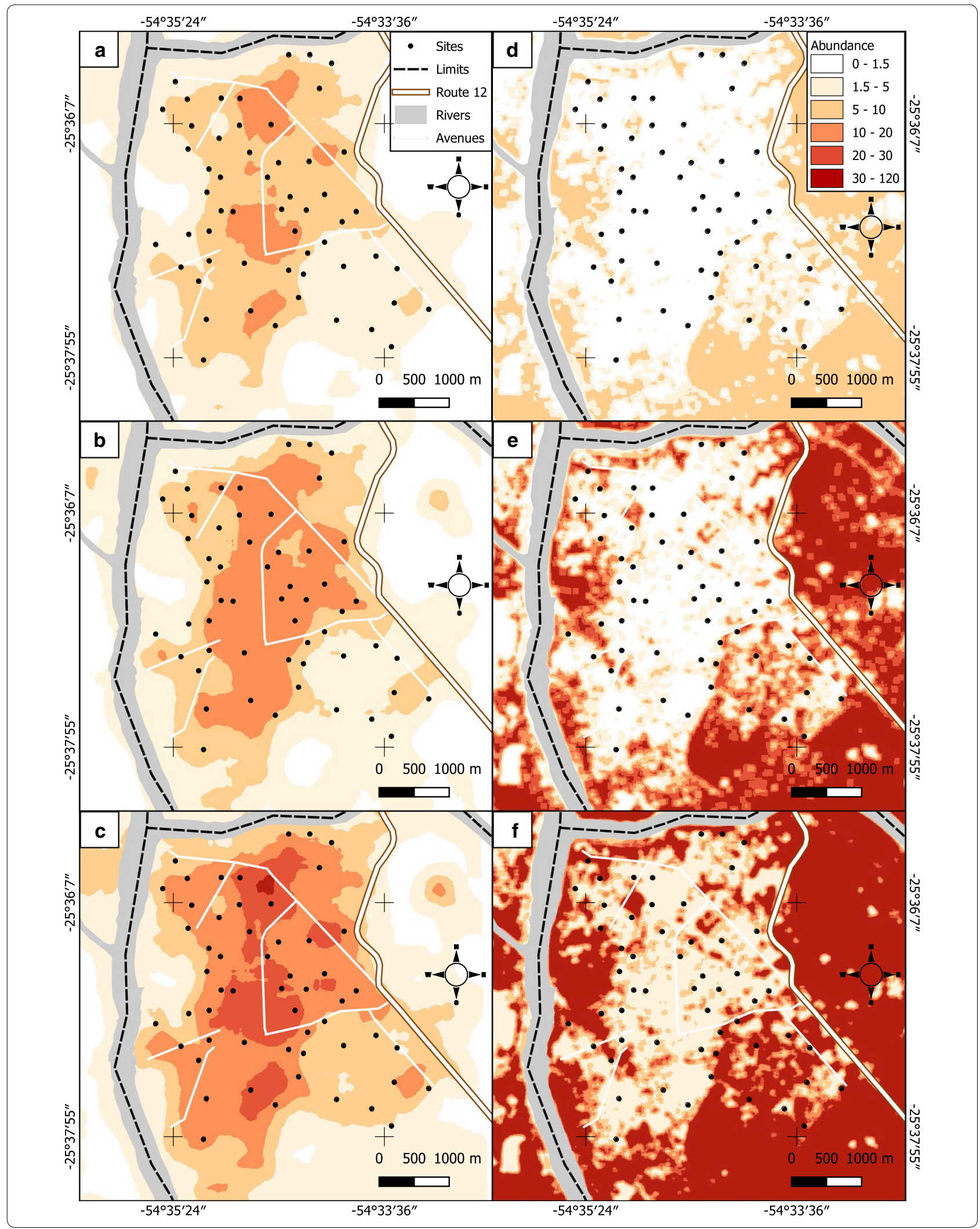


Table 4 Parameter estimates of the zero-inflated negative binomial models for Nyssomyia whitmani abundance

\begin{tabular}{|c|c|c|c|c|c|c|}
\hline \multirow[t]{2}{*}{ Variable } & \multicolumn{3}{|c|}{ Negative binomial } & \multicolumn{3}{|c|}{ Zero-inflated } \\
\hline & Coefficient & SE & $P$-value & Coefficient & SE & $P$-value \\
\hline Intercept & -7.72 & 1.89 & $<0.001$ & -0.44 & 0.41 & 0.28 \\
\hline \multicolumn{7}{|l|}{ Mesoscale } \\
\hline Tree percentage in 50-m radius area & 0.04 & 0.01 & $<0.001$ & & & \\
\hline Garbage collection service & 3.09 & 1.42 & 0.030 & & & \\
\hline \multicolumn{7}{|l|}{ Microscale } \\
\hline Log (no. of hosted people) & 1.99 & 0.88 & 0.023 & & & \\
\hline Chickens presence & 1.47 & 0.63 & 0.019 & & & \\
\hline
\end{tabular}

Notes: Parameters estimated are shown in the linear predictor scale. AIC: 187.98 (null model: 207.85); 83 residuals degrees of freedom

in the forecasting map with 50-m microscale windows, the spatial buffer that best explains the variance of this species, shows the continuous peripheral distribution of $N y$. whitmani in riparian forest, and the city green belt continuous with the secondary and preserved forest around the city. Nyssomyia whitmani also seems ornithophilic and anthropophilic but less cynophilic, as suggested by the positive effect of poultry or clustered humans on the distribution of the abundance of this species at the microscale. Regarding the association with rural and forest landscapes, $N y$. whitmani in some regions of Brazil are still not urbanized or are in process of urbanization as in the present study [64-67], while in other regions the species is well adapted to urban environments. However, this species may actually represent a complex of cryptic species with different degrees of adaptation to anthropized environments $[68,69]$. The unexpected association with garbage collection as an indicator or proxy of other undetermined variables requires further investigation.

Leishmania infantum DNA detection confirms the central role of $\mathrm{Lu}$. longipalpis in the VI cycle by parasite transmission in urban landscapes, mostly when it is found in specimens with empty guts, i.e. with at least a previous digested infected blood meal. Other species reported in this study were also found with DNA of $L e$. infantum in Puerto Iguazu area (Ny. whitmani, Mg. migo$n e i, N y$. neivai and Mi. quinquefer) but only Mg. migonei was suggested a role as permissive vector of Le. infantum in Argentina and Brazil [10, 29, 70-72] or as a link between urban and wild cycles of ACL $[4,45,73]$. In the season that followed this study (March 2015) Le. infantum DNA was detected in three phlebotomine $(2 \mathrm{Lu}$. longipalpis and $1 \mathrm{Mi}$. quinquefer) without a visible blood meal inside, captured in the same site as the previously infected ones suggesting the presence of a "hot spot" of parasites [71].

\section{Conclusions}

We reinforce the results about the spatial segregation of urban Lu. longipalpis and periurban-rural Ny. whitmani, and therefore the VL and CL risk, but with a potential trend of Lu. longipalpis to spread to the rural areas and of $N y$. whitmani to the urban areas $[12,13,15,17,45$, 74-77]. Further, due to the plasticity of $\mathrm{Lu}$. longipalpis, $N y$. whitmani and $M g$. migonei, the ruralized periurban ecotone could act as a bridge between the domestic and forest cycles of transmission by permissive vectors [29, $78]$, and the forested edges could be an eventual shelter for phlebotomine during chemical interventions in urban areas [79]. The modeling allowed to assess the abundance distribution of these vectors; mainly driven by NDWI, landscape structure and blood-meal availability, at two spatial scales. The high micro-heterogeneity at urban settings provided a broad gradient of resting-breeding sites and clustered meal sources for the species that better support lower environmental humidity, so $L u$. longipalpis causing human VL clustered there in "hot spots" $[15,21,46,80]$. Forecasting the urban distribution of $L u$. longipalpis abundance will allow to design and evaluate the impact of focused cost-effective surveillance only in the few sites with optimal suitability for the vector, and to perform preventive interventions just in the few persistent "hot spots" as they are eventual source populations. This approach is also supported by the low genetic diversity of Lu. longipalpis in the area [81], and the trend of VL in the southern latitude localities of South America with a low or sporadic incidence of human cases and steady prevalence among dogs [82]. The latter issues highlight the need to find strategies to effective, focused interventions for the region in urban VL settings, otherwise the cost-effectiveness of any locality-wide strategy of surveillance or control would not be acceptable at a low incidence of VL in humans, facing other local priorities of human public health. 


\section{Supplementary information}

Supplementary information accompanies this paper at https://doi. org/10.1186/s13071-020-04379-6.

Additional file 1: Figure S1. Spatial predictions of the abundance (number of individuals catch in three nights) of Lu. longipalpis (a-b) and Ny. whitmani (c). a Without services, dogs or poultry. b Without services and with poultry. c Without garbage collection service, one hosted people and without poultry.

\section{Abbreviations}

CL: Cutaneous leishmaniasis; VL: Visceral leishmaniasis; GPS: Global positioning system; NDVI: Normalized difference vegetation index; NDWI: Normalized difference water index; CCA: Canonical correspondence analysis; AIC: Akaike's information criterion; Zl: Zero-inflated.

\section{Acknowledgements}

The authors would like to thank the families who opened their homes to us in order to carry out this study, Luciana Martínez Calsina INTA, Famaillá, Tucumán, Argentina, for her critical review of the English text, and all those who participated and helped in field and laboratory work (UNT, INMeT, CeNDIE, CONAE) and especially to Zaida Yadón for her valuable contributions.

\section{Authors' contributions}

ODS, MGQ and MSS conceptualized the study. MGQ, RC, MSF and AP carried out the formal analysis. ODS acquired the funding. MGQ, MSS, MFM, JMDM, SLM and MGG performed the investigation. MGQ, MSS, RC, DJL and ODS designed the study and defined the methodology. ODS carried out the project administration and supervision. MGQ wrote the original draft of the manuscript and MGQ, MSS, RC, SLM and ODS wrote, reviewed and edited the manuscript. All authors read and approved the final manuscript.

\section{Funding}

This study received support from the International Development Research Centre - IDRC- Canada project (grant number 107577-001; https://www.idrc ca/en/project/addressingemergence-and-spread-leishmaniasis-bordersarg entina-brazil-and-paraguay) and the Instituto Nacional de Medicina Tropical, Ministerio de Salud de la Nación, Argentina.

\section{Availability of data and materials}

Data supporting the conclusions of this article are included within the article and its additional file. The datasets used and/or analysed during the present study are available from the corresponding author upon reasonable request.

\section{Ethics approval and consent to participate}

The procedures were approved by the ethical committee (CEIC, Dr Carlos Barclay Office for Human Research Protection, IRB Registration 00001678-USA; Res. No. 1108/26/2014), and all the field sampling in peridomestic environments included informed consent. The householders were informed about the results with the guarantee of confidentiality, together with prevention recommendations based on environmental management.

\section{Consent for publication}

Not applicable.

\section{Competing interests}

The authors declare that they have no competing interests.

\footnotetext{
Author details

${ }^{1}$ Instituto Nacional de Medicina Tropical, Administración Nacional de Laboratorios e Institutos de Salud (ANLIS), Ministerio de Salud de la Nación, Puerto Iguazú, Misiones, Argentina. ${ }^{2}$ Instituto Superior de Entomología, Facultad de Ciencias Naturales e Instituto Miguel Lillo, Universidad Nacional de Tucumán, San Miguel de Tucumán, Argentina. ${ }^{3}$ Consejo Nacional de Investigaciones Científicas y Técnicas (CONICET), Buenos Aires, Argentina. ${ }^{4}$ Leishmaniasis Investigation Network of Argentina (REDILA), Buenos Aires, Argentina. ${ }^{5}$ Centro Nacional de Diagnóstico e Investigación en Endemo-epidemias Administración Nacional de Laboratorios e Institutos de Salud, Ministerio de Salud de
}

la Nación, Buenos Aires, Argentina. ${ }^{6}$ Departamento de Ecología, Genética y Evolución, Facultad de Ciencias Exactas y Naturales (FCEN), Universidad de Buenos Aires e Instituto de Ecología, Genética y Evolución, CONICET, Buenos Aires, Argentina. ${ }^{7}$ Laboratorio de Biología Molecular Aplicada, Facultad de Ciencias Exactas, Químicas y Naturales, Universidad Nacional de Misiones, Posadas, Misiones, Argentina. ${ }^{8}$ Grupo de Bioestadística Aplicada, Departamento de Ecología, Genética y Evolución, FCEN, Universidad de Buenos Aires, Buenos Aires, Argentina.

Received: 4 March 2020 Accepted: 24 September 2020

Published online: 02 October 2020

\section{References}

1. WHO. Control of leishmaniasis: report of the meeting of the WHO Expert Commitee on the control of leishmaniases. Geneva: World Health Organization; 2010. https://apps.who.int/iris/handle/10665/44412.

2. PAHO. Plan of action for the elimination of neglected infectious diseases and post-elimination actions 2016-2022. Resolution CD55/15. 2016. Washington: Pan American Health Organization; 2016. http://iris.paho. org/xmlui/handle/123456789/31434.

3. Salomón O, Sinagra A, Nevot M, Barberian G, Paulin P, Estévez JO, et al. First visceral leishmaniasis focus in Argentina. Mem Inst Oswaldo Cruz. 2008;103:109-11.

4. Quintana MG, Fernández MS, Salomón OD. Distribution and abundance of Phebotominae, vectors of leishmaniasis, in Argentina: spatial and temporal analysis at different scales. J Trop Med. 2012;2012:652803.

5. Salomon OD. Instructions on how to make an outbreak of American cutaneous leishmaniasis. J Trop Med Health. 2019;3:146.

6. Salomon OD, Wilson ML, Munstermann LE, Travi BL. Spatial and temporal patterns of Phlebotominae sand flies (Diptera: Psychodidae) in a cutaneous leishmaniaisis focus in northern Argentina. J Med Entomol. 2004;41:33-9.

7. Quintana MG, Salomon OD, De Grosso LMS. Distribution of phlebotomine sand flies (Diptera: Psychodidae) in a primary forest-crop interface, Salta, Argentina. J Med Entomol. 2010;47:1003-10.

8. Salomón OD, Orellano PW. Lutzomyia longipalpis in Clorinda, Formosa Province, an area of potential visceral leishmaniasis transmission in Argentina. Mem Inst Oswaldo Cruz. 2005;100:475-6.

9. Salomón OD, Mastrangelo AV, Santini MS, Liotta DJ, Yadon ZE. Retrospective eco-epidemiology as a tool for the surveillance of leishmaniasis in Misiones, Argentina, 1920-2014. Rev Panamericana de Salud Pública. 2016:40:29-39.

10. Salomón OD, Quintana MG, Bezzi G, Morán ML, Betbeder E, Valdez DV Visceral leishmaniasis focus without Lutzomyia longipalpis in La Banda, Argentina. Acta Trop. 2010;113:84-7.

11. Salomón OD, Feliciangeli MD, Quintana MG, Afonso MM, Rangel EF. Lutzomyia longipalpis urbanisation and control. Mem Inst Oswaldo Cruz. 2015;110:831-46.

12. Salomón OD, Orellano PW, Quintana MG, Pérez S, Sosa Estani S, Acardi $\mathrm{S}$, et al. Transmisión de la leishmaniasis tegumentaria en Argentina. Medicina. 2006:66:211-9.

13. Salomón OD, Acardi SA, Liotta DJ, Fernández MS, Lestani E, López D, et al. Epidemiological aspects of cutaneous leishmaniasis in the lguazú falls area of Argentina. Acta Trop. 2009;109:5-11.

14. Fernández MS, Fraschina J, Acardi S, Liotta DJ, Lestani E, Giuliani MG, et al. Assessment of the role of small mammals in the transmission cycle of tegumentary leishmaniasis and first report of natural infection with Leishmania braziliensis in two sigmodontines in northeastern Argentina. Parasitol Res. 2017;117:405-12.

15. Santini MS, Fernández MS, Cavia R, Salomón OD. Co-occurrence and seasonal and environmental distributions of the sandflies Lutzomyia longipalpis and Nyssomyia whitmani in the city of Puerto lguazú, northeastern Argentina. Med Vet Entomol. 2017;32:197-205.

16. Gould IT, Perner MS, Santini MS, Saavedra SB, Bezzi G, Maglianese MI, et al. Visceral leishmaniasis in Argentina Cases notification and distribution of vectors (2006-2012). Medicina. 2013;73:104-10. 
17. Santini MS, Gould IT, Manteca Acosta M, Acardi SA, Fernández MS, Gómez A, et al. Phlebotominae of sanitary interest in the Argentina-Brazil-Paraguay border area. Rev Inst Med Trop Sao Paulo. 2013;55:239-43.

18. Oyarzabal M, Clavijo J, Oakley L, Biganzoli F, Tognetti P, Barberis I, et al. Vegetation units of Argentina. Ecol Austral. 2018;28:40-63.

19. Peel MC, Finlayson BL, McMahon TA. Updated world map of the Köppen-Geiger climate classification. Hydrol Earth Syst Sci. 2007;4:439-73.

20. Fernández MS, Santini MS, Cavia R, Sandoval AE, Pérez AA, Acardi S, et al. Spatial and temporal changes in Lutzomyia longipalpis abundance, a Leishmania infantum vector in an urban area in northeastern Argentina. Mem Inst Oswaldo Cruz. 2013;108:817-24.

21. Fernández MS, Salomón OD, Cavia R, Perez AA, Acardi SA, Guccione $J D$, et al. Lutzomyia longipalpis spatial distribution and association with environmental variables in an urban focus of visceral leishmaniasis, Misiones, Argentina. Acta Trop. 2010;114:81-7.

22. Fernández MS, Martínez MF, Pérez AA, Santini MS, Gould IT, Salomón OD. Performance of light-emitting diode traps for collecting sand flies in entomological surveys in Argentina. J Vector Ecol. 2015;40:373-8.

23. Galati EAB. Morfologia, terminologia de adultos e identificação dos táxons da América. In: Rangel EF, Shaw J, editors. Brazilian sand flies biology, taxonomy, medical importance and control. Rio de Janeiro: Springer; 2018. p. 9-212.

24. Marcondes CB. A proposal of generic and subgeneric abbreviations for phlebotomine sandflies (Diptera: Psychodidae: Phlebotominae) of the world. Entomol News. 2007;118:351-6.

25. Szelag EA, Rosa JR, Galati EAB, Andrade Filho JD, Salomón OD. Considerations on the species complex of the cortelezzii series (Diptera: Psychodidae) and description of Evandromyia chacuensis sp. nov., a new phlebotomine species of the Chaco Region. Argentina. J Med Entomol. 2018:55:902-9.

26. Lins RMMA, Oliveira SG, Souza NA, de Queiroz RG, Justiniano SCB, Ward RD, et al. Molecular evolution of the cacophony IVS6 region in sandflies. Insect Mol Biol. 2002;11:117-222.

27. Lachaud L, Marchergui-Hammami S, Chabbert E, Dereure J, Dedet JP, Bastien P. Comparison of six PCR methods using peripheral blood for detection of canine visceral leishmaniasis. J Clin Microbiol. 2002:40:210-5.

28. Santini MS, Utgés ME, Berrozpe P, Manteca Acosta M, Casas N, Heuer $P$, et al. Lutzomyia longipalpis presence and abundance distribution at different micro-spatial scales in an urban scenario. PLoS Negl Trop Dis 2015:9:e0003951.

29. Thomaz-Soccol V, Gonçalves AL, Piechnik CA, Baggio RA, Boeger WA, Buchman TL, et al. Hidden danger: unexpected scenario in the vectorparasite dynamics of leishmaniases in the Brazil side of triple border (Argentina, Brazil and Paraguay). PLoS Negl Trop Dis. 2018;12:e0006336.

30. Tucker CJ. Red and photographic infrared linear combination for monitoring vegetation. Remote Sens Environ. 1979;8:127-50.

31. Gao BC. NDWI a normalized difference water index for remote sensing of vegetation liquid water from space. Remote Sens Environ. 1996:58:257-66

32. Coulibaly L, Goïta K. Evaluation of the potential of various spectral indices and textural features derived from satellite images for surficial deposits mapping. Int J Remote Sens. 2006;27:4567-84.

33. Landis RJ, Koch GG. The measurement of observer agreement for categorical data. Biometrics. 1977;33:159-74.

34. QGIS Development Team. QGIS Geographic Information System. Open source geospatial foundation project. 2014. http://qgis.osgeo.org.

35. Seber GAF. The estimation of animal abundance and related parameters. London: Charles Griffin; 1982.

36. Gotelli N, Colwell RK. Quantifying biodiversity: procedures and pitfalls in the measurement and comparison of species richness. Ecol Lett. 2001;4:379-91.

37. Legendre P. Interpreting the replacement and richness difference components of beta diversity. Glob Ecol Biogeogr. 2014;23:1324-34.

38. Zuur A, leno EN, Walker N, Saveliev AA, Smith GM. Mixed effects models and extensions in ecology with R. New York: Springer Science \& Business Media; 2009.

39. Oksanen AJ, Blanchet FG, Friendly M, Kindt R, Legendre P, McGlinn D, et al. Vegan: Community Ecology Package. R Package Version 2.0-2. https:// CRAN.R-project.org/package $=$ vegan.
40. R Development Core Team. R: A language and environment for statistical computing. R Vienna: Foundation for Statistical Computing; 2017. https:// www.R-project.org/

41. Wenger SJ, Freeman MC. Estimating species occurrence, abundance, and detection probability using zero inflated distributions. Ecology. 2008;89:2953-9.

42. Santini MS, Fernández MS, Cavia R, Salomón OD. Co-occurrence and seasonal and environmental distributions of the sandflies Lutzomyia longipalpis and Nyssomyia whitmani in the city of Puerto Iguazú, northeastern Argentina. Med Vet Entomol. 2018;32:197-205.

43. Aguiar GM, Medeiros WM. Distribuição regional e habitats das espécies de flebotomíneos do Brasil. In: Rangel EF, Lainson R, editors. flebotomíneos do Brasil. Rio de Janeiro: Fiocruz; 2003. p. 207-55.

44. Quintana MG, Salomón OD, Guerra R. Lizarralde de Grosso MS, Fuenzalida AD Phlebotominae of epidemiological importance in cutaneous leishmaniasis in northwestern Argentina: risk maps and ecological niche models. Med Vet Entomol. 2013;27:39-48.

45. Fernández MS, Lestani E, Cavia R, Salomón OD. Phlebotominae fauna in a recent deforested area with American tegumentary leishmaniasis transmission (Puerto Iguazú, Misiones, Argentina): seasonal distribution in domestic and peridomestic environments. Acta Trop. 2012;122:16-23.

46. Berrozpe P, Lamattina D, Santini MS, Araujo AV, Utgés ME, Salomón OD. Environmental suitability for Lutzomyia longipalpis in a subtropical city with a recently established visceral leishmaniasis transmission cycle, Argentina. Mem Inst Oswaldo Cruz. 2017;112:674-80.

47. Dos Santos Silva J, Caranha L, Moura Santos FK, Dos Santos AP, Rodrigues da Silva LO, Rangerl FE. Sand fly (Diptera, Psychodidae, Phlebotominae) abundance and diversity in areas affected by the São Francisco River transposition project in Ceará State, Brazil. Parasit Vectors. 2017;10:403.

48. Machado TDO, Minuzzi-Souza TTC, Ferreira TS, Freire LP, Timbó RV, Vital TE, et al. The role of gallery forests in maintaining Phlebotominae populations: potential Leishmania spp. vectors in the Brazilian savanna. Mem Inst Oswaldo Cruz. 2017;112:681-91.

49. Ribeiro da Silva RC, Guimarães E, Silva AS, da Silva Sousa SS, Bezerra JMT, Rebêlo JMM, et al. Occurrence of Phlebotominae (Diptera: Psychodidae) in urban leishmaniasis transmission foci in north-eastern Brazil. J Med Entomol. 2019;56:247-53.

50. Pereira Filho AA, Bandeira Mda C, Fonteles RS, Moraes JL, Lopes CR, Melo $M N$, et al. An ecological study of sand flies (Diptera: Psychodidae) in the vicinity of Lençóis Maranhenses National Park, Maranhão. Brazil. Parasit Vectors. 2015;8:442

51. Alexander B, de Carvalho RL, McCallum H, Pereira MH. Role of the domestic chicken (Gallus gallus) in the epidemiology of urban visceral leishmaniasis in Brazil. Emerg Infect Dis. 2002;8:1480-5.

52. de Andrade AR, da Silva BA, Cristaldo G, de Andrade SM, Filho AC, Ribeiro $A$, et al. Spatial distribution and environmental factors associated to phlebotomine fauna in a border area of transmission of visceral leishmaniasis in Mato Grosso do Sul. Brazil. Parasit Vectors. 2014;7:260.

53. Saraiva $L$, Andrade Filho JD, Falcão AL, de Carvalho DA, de Souza CM, Freitas CR, et al. Phlebotominae fauna (Diptera: Psychodidae) in an urban district of Belo Horizonte, Brazil, endemic for visceral leishmaniasis: characterization of favored locations as determined by spatial analysis. Acta Trop. 2011;17:137-45.

54. Santini MS, Fernández MS, Pérez AA, Sandoval EA, Salomón OD. Lutzomyia longipalpis abundance in the city of Posadas, northeastern Argentina: variation at different spatial scales. Mem Inst Oswaldo Cruz. 2012;107:767-71.

55. Legriffon CM, Reinhold-Castro KR, Fenelon VC, Neitzke-Abreu HC, Teodoro $U$. Sandfly frequency in a clean and well-organized rural environment in the state of Paraná. Brazil. Rev Soc Bras Med Trop. 2012;45:77-82.

56. Prestes-Carneiro LE, Daniel LAF, Almeida LC, D'Andrea LZ, Vieira AG, Anjolete IR, et al. Spatiotemporal analysis and environmental risk factors of visceral leishmaniasis in an urban setting in São Paulo State. Brazil. Parasit Vectors. 2019;12:251.

57. Salomón OD, Quintana MG, Bruno MR, Quiriconi RV, Cabral V. Visceral leishmaniasis in border areas: clustered distribution of phlebotomine sand flies in Clorinda. Argentina. Mem Inst Oswaldo Cruz. 2009;104:801-4.

58. Vianna EN, Morais MH, Almeida AS, Sabroza PC, Reis IA, Dias ES, et al. Abundance of Lutzomyia longipalpis in urban households as risk factor of transmission of visceral leishmaniasis. Mem Inst Oswaldo Cruz. 2016:111:302-10. 
59. Menezes JA, Ferreira EC, Andrade-Filho JD, de Sousa AM, Morais MH, Rocha $M$, et al. An integrated approach using spatial analysis to study the risk factors for leishmaniasis in area of recent transmission. Biomed Res Int. 2015;2015:621854.

60. Holcman MM, Sampaio SM, Rangel O, Casanova C. Spatial and seasonal distribution of Lutzomyia ongipalpis in Dracena, a city in the western region of the State of São Paulo, Brazil, that is endemic with visceral leishmaniasis. Rev Soc Bras Med Trop. 2013;46:704-12.

61. Gómez-Bravo A, German A, Abril M, Scavuzzo M, Salomón OD. Spatial population dynamics and temporal analysis of the distribution of Lutzomyia longipalpis (Lutz \& Neiva, 1912) (Diptera: Psychodidae: Phlebotominae) in the city of Clorinda, Formosa, Argentina. Parasit Vectors. 2017:10:352.

62. Berrozpe PE, Lamattina D, Santini MS, Araujo AV, Torrusio SE, Salomón OD. Spatiotemporal dynamics of Lutzomyia longipalpis and macro-habitat characterization using satellite images in a leishmaniasis-endemic city in Argentina. Med Vet Entomol. 2019;33:89-98.

63. Oliveira AG, Galati EA, de Oliveira O, de Oliveira GR, Espindola IA, Dorval $\mathrm{ME}$, et al. Abundance of Lutzomyia longipalpis (Diptera: Psychodidae: Phlebotominae) and urban transmission of visceral leishmaniasis in Campo Grande, state of Mato Grosso do Sul, Brazil. Mem Inst Oswaldo Cruz. 2006;101:869-74.

64. Dorval ME, Oshiro ET, Brilhante AF, Nunes VL, Cristaldo G, Lima Júnior MS, et al. Sandflies in an urban area of transmission of visceral leishmaniasis in midwest Brazil. Parasite. 2016;23:35.

65. Vieira VR, Azevedo AC, Alves JR, Guimarães AE, Aguiar GM. Phlebotomine sand flies (Diptera, Psychodidae, Phlebotominae) in areas of American cutaneous leishmaniasis, in the Municipality of Paraty, Rio de Janeiro, Brazil. I. Index of abundance by location and type of capture. J Med Entomol. 2015;52:886-95.

66. Souza NA, Silva JB, Godoy RE, Souza FJ, Andrade-Coelho CA, Silva VC, et al. Studies on Phlebotominae (Diptera: Psychodidae) in the campus Fiocruz mata Atlântica, Jacarepaguá, in the city of Rio de Janeiro, Brazil. Rev Soc Bras Med Trop. 2015;48:26-32.

67. Pinheiro MP, Silva JH, Cavalcanti KB, de Azevedo PR, de Melo Ximenes M. Ecological interactions among phlebotomines (Diptera: Psychodidae) in an agroforestry environment of northeast Brazil. J Vector Ecol. 2013;38:307-16.

68. Lainson R. Ecological interactions in the transmission of the leishmaniasis. Philos Trans R Soc Lond B. 1988;321:389-404

69. da Costa SM, Cechinel M, Bandeira V, Zannuncio JC, Lainson R, Rangel EF. Lutzomyia (Nyssomyia) whitmani s.l. (Antunes \& Coutinho, 1939) (Diptera: Psychodidae: Phlebotominae): geographical distribution and the epidemiology of American cutaneous leishmaniasis in Brazil -mini-review. Mem Inst Oswaldo Cruz. 2007;102:149-53.

70. Moya SL, Giuliani MG, Acosta MM, Salomón OD, Liotta DJ. First description of Migonemyia migonei (França) and Nyssomyia whitmani (Antunes \& Coutinho) (Psychodidae: Phlebotominae) natural infected by Leishmania infantum in Argentina. Acta Trop. 2015;152:181-4.
71. Moya SL, Giuliani MG, Santini MS, Quintana MG, Salomón OD, Liotta DJ. Leishmania infantum DNA detected in phlebotomine species from Puerto Iguazú City, Misiones Province, Argentina. Acta Trop. 2017;172:122-4.

72. de Carvalho MR, Valenca HF, da Silva FJ, Pita-Pereira D, Araújo Pereira T, Britto C, et al. Natural Leishmania infantum infection in Migonemyia migonei (Franca, 1920) (Diptera: Psychodidae: Phlebotominae) the putative vector of visceral leishmaniasis in Pernambuco State, Brazil. Acta Trop. 2010;116:108-10

73. Chaves LF, Añez N. Species co-occurrence and feeding behavior in sand fly transmission of American cutaneous leishmaniasis in western Venezuela. Acta Trop. 2004;92:219-24

74. Colla-Jacques FE, Casanova C, Prado AP. Study of sand fly fauna in an endemic area of American cutaneous leishmaniasis and canine visceral leishmaniasis in the municipality of Espírito Santo do Pinhal, São Paulo. Brazil. Mem Inst Oswaldo Cruz. 2010;105:208-15.

75. Rangel EF, Lainson R. Ecologia das leishmanioses. In: Rangel EF, Lainson R (Eds.), Flebotomíneos do Brasil. Rio de Janeiro: Fiocruz Ed.; 2003. p. 291-336.

76. Teodoro U, Alberton D, Kühl JB, Santos ES, Santos DR, Santos AR, et al. Ecologia de Lutzomyia (Nyssomyia) whitmani em área urbana do município de Maringá. Paraná. Rev Saude Publ. 2003;37:651-6.

77. Salomón OD, Rossi GC, Spinelli GR. Ecological aspects of Phelobotomine (Diptera: Psychodidae) in an endemic area of tegumentary leishmaniasis in the northeastern Argentina, 1993-1998. Mem Inst Oswaldo Cruz. 2002:97:163-8.

78. Guimarães VCFV, Pruzinova K, Sadlova J, Volfova V, Myskova J, Filho SPB, et al. Lutzomyia migonei is a permissive vector competent for Leishmania infantum. Parasit Vectors. 2016;9:159.

79. Oliveira AG, Galati EA, Fernandes CE, Dorval ME, Brazil RP. Ecological aspects of phlebotomines (Diptera: Psychodidae) in endemic area of visceral leishmaniasis, Campo Grande, State of Mato Grosso do Sul, Brazil. J Med Entomol. 2012;49:43-50.

80. Lana RS, Michalsky ÉM, Lopes LO, Lara-Silva FO, Nascimento JL, et al. Ecoepidemiological aspects of visceral leishmaniasis in an endemic area in the Steel Valley in Brazil: an ecological approach with spatial analysis. PLOS ONE. 2018;13:e0206452.

81. Pech-May A, Ramsey JM, González Ittig RE, Giuliani M, Berrozpe P, Quintana MG, et al. Genetic diversity, phylogeography and molecular clock of the Lutzomyia longipalpis complex (Diptera: Psychodidae). PLoS Neg Trop Dis. 2018;12:e0006614.

82. Lamattina D, Berrozpe PE, Casas N, Moya SL, Giuliani MG, Costa SA, et al. Twice upon a time: the progression of canine visceral leishmaniasis in an Argentinean city. PLoS ONE. 2019;14:e0219395.

\section{Publisher's Note}

Springer Nature remains neutral with regard to jurisdictional claims in published maps and institutional affiliations. 